\title{
50. Breakdown of a Seamount on the Slope of the Japan Trench
}

\author{
By Akio Mogi and Kunikazu NishizawA \\ Hydrographic Department, Maritime Safety Agency \\ (Communicated by Chuji Tsubor, M. J. A., May 12, 1980)
}

A detailed survey of the sea bottom topography which was made recently around the seamount Kashima No. $1\left(\varphi=38.6^{\circ} \mathrm{N}, \lambda=142.6^{\circ} \mathrm{E}\right)$ near the Japan trench has disclosed its peculiarly asymmeteric form, indicating that a breakdown must have taken place on an old seamount in the $\mathrm{N}-\mathrm{S}$ direction, leaving its eastern split half now to be seen as Kashima No. 1.

The survey was made over a wide area including this seamount by the Hydrographic Department in 1976-1977 by means of continuous air gun profiling. It was done along the series of parallel lines in the $\mathrm{E}-\mathrm{W}$ direction at 2 mile spacings and those in the $\mathrm{N}-\mathrm{S}$ direction at 20 mile spacings.

The bottom topography found by the survey is shown in Fig. 1, in which the part of the Japan trench deeper than $7500 \mathrm{~m}$ is shaded. Kashima No. 1 is situated just on the oceanward slope of the Japan trench. The base of the seamount is semi-circular in shape and extends $50 \mathrm{~km}$ in the $\mathrm{N}-\mathrm{S}$ and $30 \mathrm{~km}$ in the $\mathrm{E}-\mathrm{W}$ directions. The top of the seamount is $3600-3800 \mathrm{~m}$ deep and has a flat plane $\mathrm{A}$, which is $16 \mathrm{~km}$ in the NE-SW and $10 \mathrm{~km}$ in the NW-SE directions. The plane is covered by sediments, about $200 \mathrm{~m}$ thick, of the Cretaceous Period, slightly dipping westward. The flat plane is about $2000 \mathrm{~m}$ deeper as compared with the case of other seamounts indicating that Kashima No. 1 is already on the oceanward slope of the Japan trench.

Unlike other ordinary seamounts, Kashima No. 1 has a very asymmetric shape. On the southeastern side, it slopes down more or less uniformly in all radial directions from the top, while on the opposite side, it faces the Japan trench across a steep slope running along a straight line in the NE-SW direction as shown in Fig. 2.

A remarkable thing is that a big rise is seen on the trench bottom to the immediate west of Kashima No. 1 across the straight line and that another flat plane B is seen at its top. The plane B is $5200-5400 \mathrm{~m}$ deep and is therefore 1500 deeper than the plane A of Kashima No. 1. Compared with the bottom of the Japan trench which is about $7500 \mathrm{~m}$ deep around here, the plane B is $2000 \mathrm{~m}$ shallower. Fig. 3 shows a diagrammatical $\mathrm{E}-\mathrm{W}$ cross section across these levels. The flat 


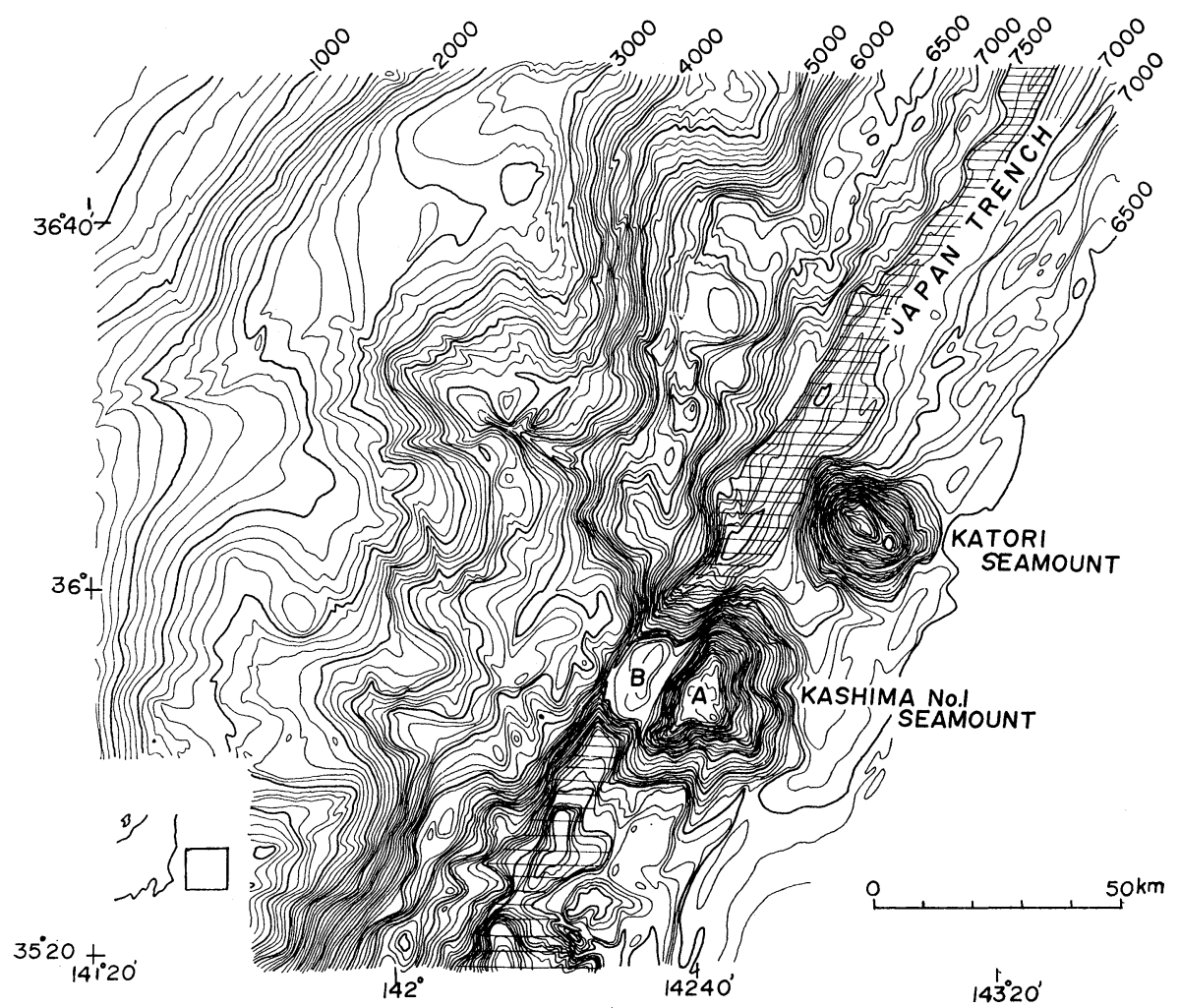

Fig. 1. Sea bottom topography around Kashima No. 1.

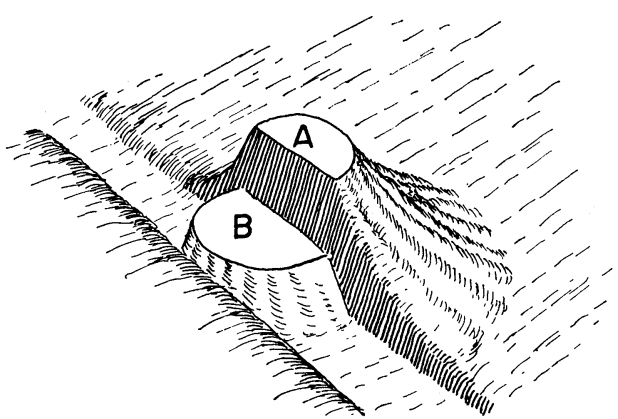

Fig. 2. Breakdown of the old seamount on the slope of the Japan trench.

plane $B$ is $20 \mathrm{~km} \times 10 \mathrm{~km}$ in extension and is also covered by old sediments as the plane $\mathrm{A}$. This big rise cannot be the results of accretion of soft sediments within the trench.

Judging from these facts, it is very likely that the planes A and B were one continuous feature at the top of a large seamount before. If all the bathymetric values around the plane $B$ are reduced by $1500 \mathrm{~m}$ 


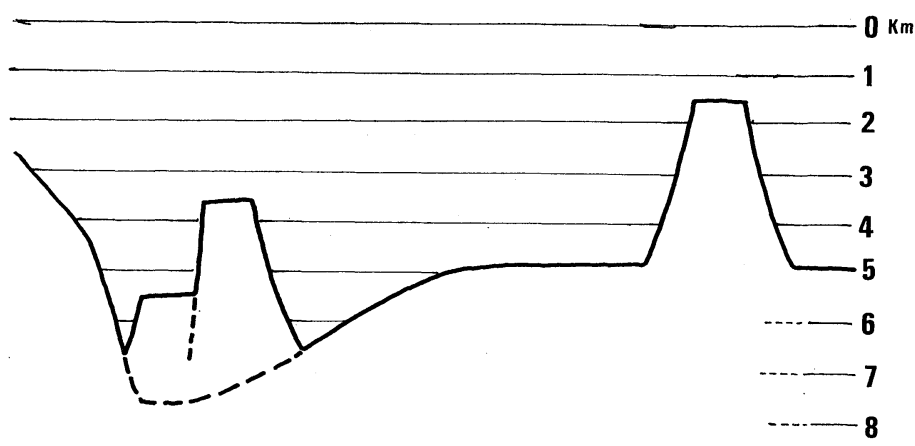

Fig. 3. E-W profile of the sea bottom across Kashima No. 1.

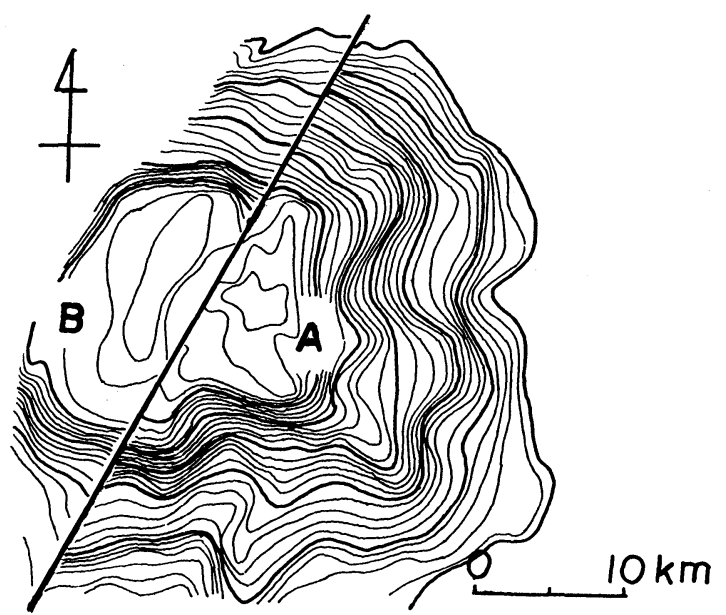

Fig. 4. Restoration of the old seamount.

and drawn together with the values around the plane $A$, they join very smoothly as in Fig. 4 and form a conical shape like other seamounts.

All this shows that a breakdown must have taken place on an old seamount along a fracture line parallel to the trend of the Japan trench and divided into two halves. The eastern half is still existing at its original position to be seen as Kashima No. 1, while the western half was drug down into the Japan trench.

The results of the magnetic surveys which have been made over this area also support the occurrence of the breakdown. What has been found here adds one favorable evidence for the subduction process which is believed to be taking place near oceanic trenches according to plate tectonic theory. 